\title{
Contamination by the Israeli Military Industry and its Impact on Apartment Sale Prices in an Adjacent Tel-Aviv Neighborhood: A Hedonic Pricing Model Study
}

\author{
by \\ Itai Shelem \\ Dr. Randall Kramer, Advisor \\ April 2008
}

Masters project submitted in partial fulfillment of the requirements for the Master of Environmental Management degree in the Nicholas School of the Environment and Earth Sciences of Duke University 


\begin{abstract}
Contamination by the Israeli Military Industry and its Impact on Apartment Sale Prices in an Adjacent Tel-Aviv Neighborhood: A Hedonic Pricing Model Study
\end{abstract}

A window of opportunity opened to investigate present effects of past environmental policies of the Israel Defense Forces and its military industry when one of its facilities, Taas Magen, was required to close down in 1997. For decades, untreated discharge was released into absorption pits, which contaminated the soil and groundwater with many toxic compounds, including the carcinogen trichloroethylene. Surrounding the industrial facility is a housing market, consisting of more than 11,000 apartments, directly affected by the contamination.

This hedonic pricing model study quantifies the effect of the environmental degradation due to the operations of Taas Magen on the nearby housing market. This was achieved by examining the effect distance away from Taas had on apartment sale prices. Results show that apartments near the facility were more negatively impacted than those further away. Next, the model was expanded to isolate the impact of the contamination from that of the facility by incorporating information regarding the public's awareness of the degradation. The resulting regression coefficients suggest that only after public acknowledgement of the harm did distance significantly impact prices. Therefore, it is the environmental contamination and not necessarily the facility that negatively impacted prices.

As a result of the contamination, the mean apartment price loss was $-\$ 24,650.74$ ('06 dollars), which is approximately $14 \%$ of an apartment's average value. Losses to the surrounding housing market are estimated at \$267 to \$287 million. These are only a minimum of the total social and economic costs incurred by the greater community, which are estimated to total at least $\$ 358$ million.

Assuming the government were to fund the estimated $\$ 33$ million cleanup costs, a minute gain of $1.5 \%$ in the value of this $\$ 2.2$ billion housing market would create the necessary economic benefit to offset the cost of decontaminating the site. Similarly, a more technologically advanced, yet expensive, iron nanoparticle remediation process would require a gain of $10.1 \%$ to offset its costs. Such market gains are not unreasonable given a drastic decrease in environmental harms. Furthermore, reclaiming a lost aquifer, reduction in human health risks, restoration of environmental integrity, and further increases to the housing market are all benefits of remediation that may greatly overshadow the concomitant cleanup costs.

Future research should focus on quantifying all these benefits. With such information at hand, it will undoubtedly become apparent that remediation is socially and economically feasible. 


\section{Table of Contents}

$\begin{array}{ll}\text { Introduction } & 3\end{array}$

$\begin{array}{ll}\text { Literature Review } & 5\end{array}$

$\begin{array}{ll}\text { Basic Model } & 7\end{array}$

$\begin{array}{ll}\text { Expanded Model } & 10\end{array}$

$\begin{array}{ll}\text { Remediation Costs } & 15\end{array}$

$\begin{array}{ll}\text { Conclusions and Policy Implications } & 15\end{array}$

$\begin{array}{ll}\text { Appendix - Data Manipulation } & 18\end{array}$

$\begin{array}{lr}\text { Citations } & 19\end{array}$ 


\section{Contamination by the Israeli Military Industry and its Impact on Apartment Sale Prices in an Adjacent Tel-Aviv Neighborhood}

\section{Introduction}

In most countries, military activity and its concomitant environmental impacts are not disclosed to the public for the sake of national security. It is therefore difficult for citizen groups and other interested parties to observe and scrutinize the environmental damage caused by the military complex. This holds especially true in Israel. Until recently, this potentially large polluting entity was considered untouchable with regard to its environmental actions and accountability. But a window of opportunity opened to investigate present effects of past environmental policies of the Israel Defense Forces (IDF) and its military industry when one of its facilities was required to close down.

According to Lavee et al. (2003), Taas Magen, an IDF chemical facility, opened in 1950 and remained operational until 1997. The facility was situated on 44,000 square meters of land near the eastern city limits of Tel-Aviv. Its main operations consisted of cleaning and coating weapons and other equipment using various treatments of chemical solvents. Up until 1981, runoff from the facility was released into pits that absorbed the untreated discharge.

Beginning in 1993, the Ministry of the Environment, along with the Department of Defense, drafted preliminary plans to close Taas Magen and relocate it to Ramat Hasharon, a city bordering northern Tel-Aviv. In addition, these plans called for cleanup efforts to begin prior to the closing of the facility. In 1996, the British company Royal Ordinance was contracted to evaluate the levels of contamination on the site. The results revealed serious soil and groundwater contamination due mainly to 
trichloroethylene (TCE) and heavy metals (Lavee et al., 2003). A second study conducted in July 2002 reiterated much of the initial findings, again emphasizing the large quantity of TCE present (Ludan, 2002).

According to the Centers for Disease Control and Prevention, TCE is "a colorless liquid which is used as a solvent for cleaning metal parts" that when ingested or inhaled at high levels "may cause nervous system effects, liver and lung damage, abnormal heartbeat, coma, and possibly death" (CDC, 2003).

The study by Ludan also found that groundwater concentrations measured at the Taas Magen site greatly exceeded the Israeli drinking water standards for several chemicals of potential concern to human health. These contaminants are not easily contained and they therefore spread beyond the borders of the military's property and into neighboring areas. Concentrations of groundwater contaminants measured at nearby wells were also above the drinking water standards and pose very credible human health risks. Consequently, the Health Ministry shut down major drinking water wells in the area (Israel Union for Environmental Defense, 2007) and more than 9,000 tons of topsoil were ultimately removed by direction of the Ministry of Environment (Lavee et al., 2003).

Beyond merely contaminating soil and drinking water sources, these noxious chemicals evaporated and accumulated in the basements of local apartment buildings, exceeding Israeli air quality standards and placing residents in danger of high-level exposure (Ludan, 2002). This restricts the use of floors located below ground-level, rendering them unsafe to accommodate anything but parking garages and storage spaces. Any new housing project would require special insulation and ventilation systems if these limitations were to be avoided. 
But in addition to the potential harm to individuals, the physical degradation to the surrounding environment, and the loss of drinking water sources, similar contamination cases often come with economic costs in the form of depreciated sale prices of nearby homes or apartments that can and should be examined as part of the greater damage caused by the polluter (Ihlanfeldt \& Taylor, 2004; Brasington \& Hite, 2005; Reichert, 1997; Kohlhase, 1991). This paper will quantify the effect of the resulting contamination from past operations at Taas Magen on the nearby housing market by examining apartment sale prices before and after public knowledge of these harms. It will also review viable remediation options and their respective costs that the government should consider when planning future cleanup efforts.

The theory and models used to quantify the economic losses to the housing market are modeled off of a similar analysis conducted by Ihlanfeldt \& Taylor (2004). These losses will be analyzed utilizing a hedonic pricing model and prices of apartments sold between the years 1997 and 2003.

\section{Literature Review}

The hedonic method is most often applied to goods or products that are sold in a single market, such as houses or cars, whose characteristics create distinct product variation within that market. The characteristics that lead to differentiation among the goods also give rise to variations in price. The hedonic method for non-market valuation relies on the prices of these differentiated goods to determine the value of the underlying characteristics (Taylor, 2003). Econometrically, this allocation of value is achieved by regressing the product price on its key characteristics.

With apartments as an example, the number of rooms and the overall size greatly influence price. The value placed by a consumer on these attributes, however, is implicit 
and must therefore be derived from the only accessible explicit value - an apartment's sales price. Characteristics such as local air quality, noise level, and vantage, which are often the main focus of non-market valuation, also directly influence price. However, the value consumers place on these attributes when purchasing a home or apartment is less obvious. In some circumstances, the hedonic method is able to obtain those values. In the housing market that surrounds Taas Magen, the hedonic model may be better equipped to derive the negative value placed on the facility's environmental degradation than other methods of analysis.

A study conducted by Lavee et al. (2003) evaluated the possible economic costs and benefits of relocating Taas Magen from Tel-Aviv to Ramat Hasharon. With assistance from the tax department at the Israel Ministry of Finance, the authors were provided information on all properties sold between 1997 and 2003 in two neighborhoods adjacent to the Taas site. Their analysis of change in apartment prices was based upon an event in mid-2001 in which the Israeli government announced that preliminary cleanup efforts were mostly completed, referring to the removal of topsoil. However, groundwater contamination had not been addressed. The authors anticipated finding an increase in prices after the announcement in mid-2001. The data reflected their expectations. They then further analyzed the price differences between two neighborhoods. One neighborhood is situated directly north of the other, which houses the Taas Magen site within its boundaries. The authors therefore argued that after the preliminary cleanup efforts the neighborhood further away from Taas should see price increases greater than that of the nearer neighborhood. Again, the data reflected these expectations. Consequently, the differences in prices between these neighborhoods were then used to calculate the economic losses of the housing market of the near neighborhood. 
There are several problems in applying this methodology in the current study. First, sale prices of apartments were not normalized to account for inflation. While the raw data may show an increase in prices after the government's initial cleanup efforts, controlling for inflation may give different results and will surely affect the magnitude of economic losses between the two neighborhoods. Second, while non-normalized prices may show a difference between the neighborhoods, this difference may not be statistically significant and therefore any further analysis and conclusions based upon this difference is unfounded. In actuality, an analysis of variance conducted on prices in the separate neighborhoods concludes that, indeed, the differences between the neighborhoods were not significant. Any further analysis should therefore pool the data together and conduct further exploration on it as a whole.

\section{Basic Model}

The hedonic pricing model is an indirect valuation method based on observable market transactions along with their constituent characteristics (Rosen, 1972). Here, market transactions comprise of apartment prices sold near Taas Magen, and their characteristics consist of area in square meters, number of rooms, floor level in a multistory building, and year the building was built. Monthly national mortgage rates, state of the economy, and external conflict (data from the World Bank), were also considered as indirect macroeconomic influences on price. Descriptive statistics of these variables are outlined in Table 1. 
Table 1

\begin{tabular}{lcccc}
\cline { 2 - 5 } \multicolumn{1}{c}{ Variable } & Mean & Std. Deviation & Min & Max \\
\hline Price ('06 \$) & $198,516.90$ & $52,929.92$ & $48,447.43$ & $393,757.30$ \\
Floor & 3.048 & 1.838264 & 0 & 10 \\
Rooms & 3.308 & .6440459 & 1.5 & 6 \\
Area $\left(\mathrm{m}^{3}\right)$ & 73.964 & 16.23085 & 31 & 120 \\
Year Built & 1978.432 & 11.2005 & 1940 & 2000 \\
Distance (m) & 489.552 & 120.4869 & 189 & 746 \\
Mortgage Rate & 6.0434 & .6607657 & 4.87 & 7.08 \\
External Conflict & 6.3985 & .7109296 & 5.166667 & 7.583333 \\
State of Economy & 92.05806 & 5.271167 & 81.98697 & 101.5815 \\
\hline
\end{tabular}

To measure Taas' impact on an apartment's price, a variable characterizing distance away from the facility is incorporated into the regression. A statistically significant negative coefficient on this distance variable would categorize the facility and its contamination as disamenities and would represent their combined impact on price. In order to attribute less of this impact as distance away from the facility increases, the variable is coded as the inverse distance. The model takes on the following form:

$$
\text { Price }_{z}=\text { Constant }+\beta^{*} \text { Inverse Distance }_{z}+\text { Constituent Characteristics }_{z}+\text { Yearly Fixed Effects } s_{z}
$$

The coefficient $\beta$ represents the impact of the facility and its contamination on price. Therefore, an apartment one meter away from Taas will be fully affected by this impact, given by $\beta^{\star}(1 / 1$ meter $)$, where a similar apartment one hundred meters away will sustain a hundredth of the impact $\beta^{\star}(1 / 100$ meters $)$. 
Also included in the regression are dummy variables representing the yearly fixed effects. These are meant to capture any variation that may strongly influence price for each year between 1997 and 2003.

The regression results are outlined in Table 2.

Table 2

\begin{tabular}{|c|c|c|c|c|}
\hline Price ('06 \$) & Coeff. & Std. Err. & \multicolumn{2}{|c|}{ [95\% Conf. Interval] } \\
\hline Inverse Distance & $-7464483^{* *}$ & 3767044 & $-1.49 \mathrm{e}+07$ & -43315.45 \\
\hline Floor & $5460.062^{* * *}$ & 1352.069 & 2796.454 & 8123.67 \\
\hline Rooms & $39178.6^{* * *}$ & 6768.49 & 25844.51 & 52512.69 \\
\hline Year Built & $1098.999^{* * *}$ & 273.8709 & 559.4665 & 1638.531 \\
\hline Mortgage Rate & -2781.162 & 8470.616 & -19468.48 & 13906.15 \\
\hline External Conflict & $-8659.077^{\star}$ & 4996.231 & -18501.77 & 1183.618 \\
\hline State of Economy & $3268.418^{* *}$ & 1585.153 & 145.6289 & 6391.207 \\
\hline Year 1997 & $29976.89^{*}$ & 17557.18 & -4611.186 & 64564.96 \\
\hline Year 1998 & 17779.68 & 11308.06 & -4497.476 & 40056.84 \\
\hline Year 1999 & (dropped) & & & \\
\hline Year 2000 & $-29947.9^{* *}$ & 14056.62 & -57639.79 & -2256.019 \\
\hline Year 2001 & $-21894.91^{*}$ & 11156.87 & -43874.22 & 84.38988 \\
\hline Year 2002 & $-22286.96^{*}$ & 12482.58 & -46877.95 & 2304.034 \\
\hline Year 2003 & (dropped) & & & \\
\hline Constant & $-2333319^{* * *}$ & 580837.1 & -3477582 & -1189056 \\
\hline Observations & 250 & & & \\
\hline$R^{2}$ & 0.5319 & & & \\
\hline
\end{tabular}

Of most importance, the coefficient on the Inverse Distance variable is negative and significant at the 5\% level, while the coefficients for Floor, Rooms, and Year Built are all positive and significant. With each increment in Floor level, an apartment's price is expected to increase by nearly $\$ 5,500$, while an additional Room leads to an increase of roughly $\$ 40,000$. Note that Area was not included in the regression due to its high level of correlation with Rooms. When substituting Area for Rooms (regression not shown) the resulting statistically significant coefficient takes a value of $\$ 2,046$ per square meter - a figure quite reasonable for this region. 
The coefficient on Inverse Distance represents the negative impact Taas and its contamination have on price, which is calculated to roughly be $-\$ 7,464,000$. Given the nature of the Inverse Distance variable, the relationship between a meter increase in distance and its concomitant price change is not linear. The proper relationship is depicted in Figure 1.

Figure 1

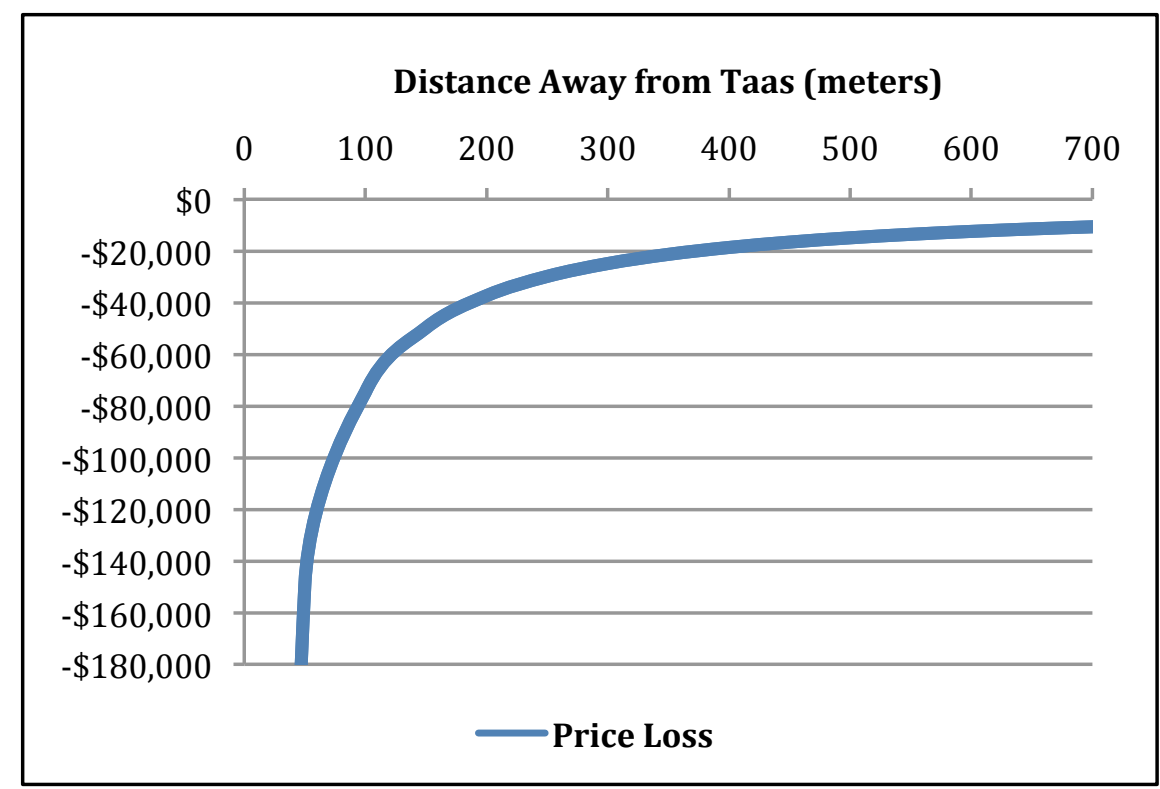

The combined negative impact of the facility and its contamination on apartment prices is quite evident. In order to isolate the impact of the contamination from that of the facility, the model must incorporate information regarding the public's knowledge and awareness of the degradation. The Expanded Model attempts achieve this isolation.

\section{Expanded Model}

In order to quantify only the effect of the contamination on the nearby housing market, the analysis must consider the impact that distance away from Taas had before and after public knowledge of these harms. This requires incorporating the analytical 
tools developed by Ihlanfeldt \& Taylor (2004) into the Basic Model previously utilized. The expansion of the model entails splitting the single Inverse Distance variable into two - Inverse Distance Before and Inverse Distance After.

Consequently, each apartment's Inverse Distance is now coded under only one of these two variables, depending upon whether the apartment was sold before or after the environmental harms became public knowledge. The unutilized variable receives a value of zero, as no apartment could be sold both before and after harm was acknowledged (except as separate transactions, on different dates, for the same apartment). Thus, each apartment receives a value for both the Inverse Distance Before and Inverse Distance After variables, however, only one such variable takes a value other than zero. For example, an apartment sold after harm was acknowledged would receive a value for Inverse Distance After associated with its distance away from Taas Magen, and zero for Inverse Distance Before.

The model takes on the following form:

Price $_{z}=$ Constant $+\beta_{1}{ }^{*}$ Inverse Distance Before ${ }_{z}+\beta_{2}{ }^{*}$ Inverse Distance After ${ }_{z}+$ Constituent Characteristics $_{z}+$ Yearly Fixed Effects

The division of the single distance variable into two distinct variables allows for the separation of impact that distance has on price, taking into consideration that differences in impact exist depending on whether transaction occurred before or after. This analysis can, therefore, test whether distance from Taas had as strong of an effect on sale prices for apartments sold before the acknowledgement of harm as compared to those sold afterwards. 
The assumption that environmental contamination negatively influenced prices can, indirectly, be validated utilizing the distance variables in the following way. If $\beta_{1}$, the coefficient on Inverse Distance Before, is not significantly different than zero and/or is significantly less than $\beta_{2}$, the coefficient on Inverse Distance After, then the assumption holds. Furthermore, the difference between the two coefficients $\left(\beta_{2}-\beta_{1}\right)$ yields the average impact, per apartment, that remnants of Taas' operations had on price. Multiplying this average impact by the number of apartments present in the surrounding neighborhoods will provide an estimate for the total economic loss to the housing market.

But for such analysis to be valid, one other assumption must hold - all apartments sold after the acknowledgement of harm must not significantly differ in their constituent characteristics from those apartments sold before. A t-test conducted on these characteristics (floor, rooms, area, and year built) definitively concludes that no significant differences exist (at the 5\% level). However, with regards to distance, apartments sold after the fact, were an average of 37 meters closer to Taas than those sold before. This difference, while significant, is quite trivial.

Lastly, in order to accurately estimate the total economic loss to the housing market, the day on which the relevant community came to acknowledge the environmental harm posed upon it must be identified. This, however, is no simple task since there is not a distinguishable day where such awareness occurred. Nevertheless, it is useful to find an approximate estimate for this date.

Throughout the year 2000, the Israel Water Commission received interim reports regarding their inquiry of aquifer contamination in the neighborhoods surrounding Taas Magen (Graber et al., 2000a, 2000b, 2001). The first report was made public in 
March of that year. This corresponds well with the trickle of related articles published in the popular media around that time. Thus, all apartment sales beginning April of 2000, approximately one month after publication, are considered sold after the acknowledgement of harm. Testing the impact distance has on price for apartments sold before and after April, separately, is the objective of the Expanded Model. The regression results for this model are outlined in Table 3.

Table 3

\begin{tabular}{|c|c|c|c|c|}
\hline \multirow{2}{*}{$\frac{\text { Price ('06 \$) }}{\text { Inverse Distance Before }}$} & \multirow{2}{*}{$\begin{array}{c}\text { Coeff. } \\
-5618506\end{array}$} & \multirow{2}{*}{$\frac{\text { Std. Err. }}{4262002}$} & \multicolumn{2}{|c|}{ [95\% Conf. Interval] } \\
\hline & & & $-1.40 \mathrm{e}+07$ & 2777924 \\
\hline Inverse Distance After & $-1.13 \mathrm{e}+07^{* *}$ & 4427690 & $-2.00 e+07$ & -2560314 \\
\hline Floor & $5424.946^{* * *}$ & 1348.577 & 2768.159 & 8081.732 \\
\hline Rooms & $39402.72^{* * *}$ & 6697.101 & 26208.99 & 52596.46 \\
\hline Year Built & $1051.967^{* * *}$ & 273.515 & 513.1242 & 1590.81 \\
\hline Mortgage Rate & -2032.532 & 8462.423 & -18704.07 & 14639.01 \\
\hline External Conflict & -3427.776 & 6675.425 & -16578.81 & 9723.257 \\
\hline State of Economy & $4114.594^{* *}$ & 1723.816 & 718.5606 & 7510.627 \\
\hline Year 1997 & 27021.18 & 17787.26 & -8020.903 & 62063.26 \\
\hline Year 1998 & 15077.07 & 11307.23 & -7198.927 & 37353.08 \\
\hline Year 1999 & (dropped) & & & \\
\hline Year 2000 & $-32967.22^{* *}$ & 14096.5 & -60738.27 & -5196.18 \\
\hline Year 2001 & $-19671.9^{*}$ & 11342.63 & -42017.63 & 2673.835 \\
\hline Year 2002 & -17673.83 & 12598.29 & -42493.3 & 7145.646 \\
\hline Year 2003 & (dropped) & & & \\
\hline Constant & $-2355200^{* * *}$ & 582820.6 & -3503395 & -1207004 \\
\hline Observations & 250 & & & \\
\hline$R^{2}$ & 0.5346 & & & \\
\hline
\end{tabular}

Note that the coefficient on Inverse Distance Before is negative, yet not significantly different than zero. This result suggests that an apartment's distance away from Taas was not a significant influence on price when the environmental degradation was not yet publicized. However, after the acknowledgement of harm distance has a significantly negative impact on price, as shown by the coefficient on Inverse Distance 
After. The fact that Inverse Distance Before is not significantly different than zero while Inverse Distance After is negative and significant suggests that prices were negatively impacted as a consequence of the environmental degradation that resulted from past operations at Taas.

The price change associated with distance is equal to the difference in estimated property price before and after the contamination. This is equal to the difference in the estimated coefficients for Inverse Distance After and Inverse Distance Before $\left(\beta_{2}-\beta_{1}\right)$, multiplied by the inverse distance of a property to Taas:

$$
\Delta \mathrm{P}_{\mathrm{z}}=\left(\beta_{2}-\beta_{1}\right){ }^{*} \text { Inverse } \text { Distance }_{z}
$$

However, coefficient $\beta_{1}$ is not significantly different than zero. Therefore, the price change associated with distance equals:

$$
\Delta \mathrm{P}_{\mathrm{z}}=\left(\beta_{2}\right){ }^{*} \text { Inverse Distance } \mathrm{D}_{\mathrm{z}}
$$

The mean price change is given by taking the mean of all the apartments' $\Delta \mathrm{P}$ in the sample. This results in a mean price difference per apartment of $-\$ 24,650.74$ ('06 dollars), which is nearly $14 \%$ of an apartment's average value within the sample. Losses ranged from a low of $\$ 15,124.88$ to a high of $\$ 59,699.25$. The economic losses within the sample of 250 apartments $\left(\sum \Delta \mathrm{P}\right)$ total $\$ 6,162,686$. Total losses to the surrounding housing market, consisting of 11,242 apartments, range between $\$ 267$ and $\$ 287$ million ${ }^{1}$.

Taking a public expenditure perspective, Lavee et al. (2003) estimates the economic costs due to past operations at Taas Magen at more than \$91 million ('06 dollars), of which more than $\$ 33$ million is allocated towards remediation of the soil and groundwater contamination. Also included are costs resulting from construction permit

\footnotetext{
${ }^{1}$ Although the Inverse Distance Before coefficient is not significantly different than zero, it may still be relevant to use its value when calculating $\Delta \mathrm{P}_{z}$. When including $\beta_{1}$ in the calculation of the mean price difference, the resulting $\Delta \mathrm{P}_{z}$ is $-\$ 12,375.78$, which is nearly $7 \%$ of an apartment's average value. Total losses to the housing market, given this mean price difference, range between $\$ 134$ and $\$ 144$ million.
} 
delays, construction limitations, new preventative measures requirements, and continual contaminant monitoring. Adding to these costs the losses to the housing market estimated by this paper, the resulting social costs total an upwards of $\$ 358$ million.

\section{Remediation Costs}

Lavee et al. (2003) estimates remediation of the soil and groundwater contamination at the Taas Magen site would cost approximately $\$ 33$ million. Similar cases of soil and groundwater TCE contamination have plagued the United States' Department of Defense, which is expected to incur cleanup costs of $\$ 5$ to $\$ 10$ billion, conditional on whether the Environmental Protection Agency decreases TCE's Maximum Contaminant Level, the highest level of a contaminant that the agency allows in drinking water (Brock, 2003). Of the more than 1,400 contaminated sites, several interesting case studies emerge that utilize new nanotechnology (iron nanoparticles) to reduce TCE levels by as much as $99.2 \%$ (Wilson, 2004).

According to Wilson (2004), this method of TCE remediation cost $\$ 95 / \mathrm{m}^{3}$ at the Naval Air Station in Jacksonville, FL and $\$ 286 / \mathrm{m}^{3}$ at Hunter's Point Shipyard in San Francisco, CA. Utilizing the cost estimates from the two case studies, cost projections for remediation of the Taas Magen site using iron nanoparticle technology range between $\$ 75$ and $\$ 226$ million.

\section{Conclusions and Policy Implications}

Contamination resulting from past operations at Taas poses direct harm to nearby residents, has degraded the surrounding environment, destroyed precious drinking water sources, and negatively impacted the local housing market. Regression 
results from the Basic Model suggest that the facility and its contamination are disamenities that negatively impact apartment sale prices. Apartments nearer to Taas sustained greater losses than those further away. The model was then expanded in an attempt to isolate the impact of the contamination from that of the facility. The resulting regression coefficients suggest that only after public acknowledgement of the harm did distance significantly impact prices. Therefore, it is the environmental contamination and not necessarily the facility that negatively impacted prices.

The mean apartment price loss was $-\$ 24,650.74$ ('06 dollars), which is approximately $14 \%$ of an apartment's average value. Losses to the surrounding housing market are estimated at $\$ 267$ to $\$ 287$ million. These are only a minimum of the total social and economic costs incurred by the greater community, which are estimated to total at least $\$ 358$ million.

Assuming the government were to fund the estimated $\$ 33$ million cleanup costs (Lavee et al., 2003), a minute gain of $1.5 \%$ in the value of this $\$ 2.2$ billion housing market would create the necessary economic benefit to offset the cost of decontaminating the site. Similarly, the more technologically advanced iron nanoparticle remediation process, which may cost as much as $\$ 226$ million, would require a gain of $10.1 \%$ to offset its costs. Such market gains are not unreasonable given a drastic decrease in environmental harms. Furthermore, given that remediation of the soil and groundwater contamination will likely result in benefits beyond mere increases to the value of the surrounding housing market, it is quite feasible that even more reliable yet expensive future remediation technologies, such as genetically engineered microorganisms (Loffler et al., 2006; Sayler et al., 2000; Kato et al., 1996), may lead to benefits (gaining an aquifer for future water use, reducing human health risks, restoring environmental 
integrity, and further increasing the housing market value) far greater than the concomitant costs.

One key concern involving remediation of contaminated sites is stigma - can property prices fully recover their lost value? It is unclear whether the housing market surrounding Taas Magen can recover 14\% of its lost value once remediation of the site is complete. It is also unclear at this moment whether the government will conduct further cleanup efforts or whether it will try to sell the land to the public as is.

Interestingly, the recent rise in the demand for Tel-Aviv apartments, partially due to the weakening of the dollar, may revitalize older neighborhoods like those surrounding Taas and create financial opportunities for private investors to purchase contaminated land to remediate and develop. Debates regarding the public sale of the Taas site and remediation liabilities are currently being conducted. Environmental groups are worried that proper remediation may not take place if the property is sold to developers, and are therefore calling for requirements of stringent remediation processes to be included in the terms of sale.

The contamination that resulted from operations at Taas Magen has had both social and economic ramifications estimated at hundreds of millions of dollars. Future research should focus on quantifying the benefits that may be realized as a result of remediation. With such information at hand, it will undoubtedly become apparent that remediation is socially and economically feasible. 


\section{Appendix - Data Manipulation}

Upon receiving the data files, certain steps were taken to prepare the data for analysis. The first involved the categorization and subsequent removal of outliers. An outlier consisted of a property whose transaction price was less than $\$ 5$, which symbolized a transfer of the property among family members, and if included would distort the regression analysis and ultimate conclusion. Four such outliers were removed. Several duplicate and erroneous data entries were also removed.

Next, transaction prices in dollars were normalized utilizing a consumer price index for private property values, for which the baseline year was 2006. Furthermore, Tel-Aviv's GIS system was utilized to calculate the properties' distances (in meters) from the Taas facility. Based upon whether the property was located south (nearer neighborhood) or north of Emek Bracha Street (further neighborhood), a binary variable was assigned 1 or 0 , respectively. This was done to test whether the two separate neighborhoods revealed price differences that were statistically significant. Lastly, a second binary variable was assigned to each property based upon the year it was sold. Properties sold prior to public knowledge of the environmental degradation in the surrounding area due to Taas (1997 to end of March, 2000) were assigned 1, while those sold after the fact (April, 2000 to 2003) were given 0.

Further data were compiled and added to the dataset to improve the validity of the analysis and its potential conclusions, such as mortgage rates, representation of economic growth, political unrest, World Development Indicators for Israel, and other relevant variables that may influence housing prices. 


\section{Citations}

Brasington, David M., and Diane Hite. "Demand for Environmental Quality: a Spatial Hedonic Analysis." Regional Science and Urban Economics 35 (2005): 57-82.

Brock, Dr. Samuel L. "New Trichloroethylene Cleanup Standards." Headquarters U.S. Air Force. 17 Apr. 2003. 10 Mar. 2008 <http:/ / www.tceblog.com/files/1400_DOD_TCE_sites.ppt>.

CDC. "ToxFAQs: Trichloroethylene (TCE)." The Agency for Toxic Substances and Disease Registry. 11 Sept. 2007. Centers for Disease Control and Prevention. $<$ http://www.atsdr.cdc.gov/tfacts19.html>.

"Central Tel Aviv: Contaminated Water and Soil." Israel Union for Environmental Defense. 13 Dec. 2007 <http:/ / www.iued.org.il/ text_item.aspx?tid=117\&menu=6>.

Graber, E, D Ronen, and S Elhanay. Contamination in the Nahalat Itzhak Area - Tel Aviv. Israel Water Commission Project Number 99-4-607. Interim Report Number I. March. 2000a.

Graber, E, D Ronen, and S Elhanay. Contamination in the Nahalat Itzhak Area - Tel Aviv. Israel Water Commission Project Number 99-4-607. Interim Report Number II. September. 2000b.

Graber, E, D Ronen, and S Elhanay. Contamination in the Nahalat Itzhak Area - Tel Aviv. Israel Water Commission Project Number 99-4-607. Interim Report Number III. July. 2001.

Ihlanfeldt, Keith, and Laura Taylor. "Externality Effects of Small-Scale Hazardous Waste Sites." Journal of Environmental Economics and Management 47 (2004): 117-139.

Kato, Kinya, and Kimberly L. Davis. "Current Use of Bioremediation for TCE Cleanup: Results of a Survey." Remediation (1996): 1-14.

Kohlhase, Janet E. "The Impact of Toxic Waste Sites on Housing Values." Journal of Urban Economics 30 (1991): 1-26.

Lavee, Doron, Amos Meller, Roni Beril, and Nir Becker. The Economic Effects of Ground Contamination by Taas Magen. Ministry of Environment, Israel. Netanya: Pareto Engineering Ltd., 2003. 1-76.

Loffler, Frank E., and Elizabeth A. Edwards. "Harnessing Microbial Activities for Environmental Cleanup." Current Opinion in Biotechnology 17 (2006): 274-284. 
Ludan Engineering Co. Ltd, and Environ International Co. . Initial Risk Survey of the Pollution of Soil, Groundwater and Air in the Tel-Aviv Region (Taas Magen Site). Ministry of the Environment, State of Israel. 2002. 1-297. <http:/ / www.sviva.gov.il/Enviroment/Static/Binaries/index_pirsumim/p0239 _1.PDF>.

Reichert, Alan K. "Impact of a Toxic Waste Superfund Site on Property Values." The Appraisal Journal 10 (1997): 381-392.

Rosen, Sherwin. "Hedonic Prices and Implicit Markets: Product Differentiation in Pure Competition." The Journal of Political Economy 82.1 (1972): 34-55.

Sayler, Gary S., and Steven Ripp. "Field Applications of Genetically Engineered Microorganisms for Bioremediation Processes." Current Opinion in Biotechnology 11 (2000): 286-289.

Taylor, Laura O. "The Hedonic Method." A Primer on Nonmarket Valuation. Ed. Patricia A. Champ, Kevin J. Boyle, and Thomas C. Brown. Boston: Kluwer Academic, 2003. 331-393.

Wilson, Greg. "Nanotechnology Applications for Remediation: Cost-Effective and Rapid Technologies; Removal of Contaminants From Soil, Ground Water; and Aqueous Environments." AAAS Science and Technology. 18 Apr. 2004. 10 Mar. 2008 <http: / / es.epa.gov/ ncer/publications/meetings / 8-1804/ppt/greg_wilson.ppt>. 


\section{Special Thanks}

Doron Lavee, PhD., Pareto engineering Ltd.

Dr. Nir Becker, Department Head of Economics and Management at Tel-Hai College, Israel

Dr. Jeffery R. Vincent, Clarence F. Korstian Professor of Forest Economics and Management, Nicholas School of the Environment and Earth Sciences, Duke University

Dr. Randall A. Kramer, Professor of Resource and Environmental Economics, Nicholas School of the Environment and Earth Sciences, Duke University 